\title{
IMPROVING THE EFFICIENCY OF OPERATION OF SUBMERSIBLE ELECTRIC CENTRIFUGAL PUMPS
}

\section{IRINA ALEKSEEVNA POGREBNAYA \& SVETLANA VIKTOROVNA MIKHAILOVA}

Industrial University of Tyumen, Russia

\begin{abstract}
Goal Explore the prospect of improving the quality of work of submersible centrifugal pumps in oil production: prevention of corrosion destruction of oil and gas production equipment units by introducing inhibitors into the formation fluid, replacing materials and pump units with new ones, applying protective coatings. These types of events are today considered one of the most urgently needed by oil industry workers. The novelty lies not in measures to ensure the quality of work, but in the technologies used. The research method is based on an analysis of the literature of domestic and foreign authors on ensuring the reliability of pumping plants, leading to a more durable operation of this equipment, the conclusion is formulated.Result. Corrosive destruction of the nodes of oil and gas production equipment, namely submersible centrifugal pumps is eliminated by five different methods. The main ones are described: the introduction of corrosion inhibitors into the formation fluid, replacement of the materials of the ESP units and body parts with new materials, in the application of corrosion-resistant metal protective coatings by high-speed gas-flame spraying based on iron, the deposition of metal anticorrosive coatings by electric arc metallization. Providing additional corrosion protection using impregnations, including fluorine-containing surfactants. The disadvantages of the methods used to protect against corrosion of ESP units are disclosed.Conclusion.Scientific achievements are determined on the basis of the analysis of the works of well-known oil industry authors. In order to increase the reliability of the operation of submersible electric centrifugal pump installations, the following measures are recommended as the most effective: introducing inhibitors into the formation fluid, replacing material units with new ones, applying protective coatings, etc. Metal and tread coatings are considered to be the most applicable anticorrosive agents, and optimization of composition, structure, and application technology is considered the most productive (FariborzKavoussi, 2013).

KEYWORDS: Installation of an Electric Drive Centrifugal Pump, Corrosion Failure \& Pumping Equipment Operability
\end{abstract}

Received: May 28, 2020; Accepted: Jun 18, 2020; Published: Jul 02, 2020; Paper Id.: IJMPERDJUN2020178

\section{INTRODUCTION}

ESP (ESP installation, installation of an electric drive centrifugal pump) refers to submersible rodless pump installations (Industrial Pumps, Screw Pump Manufacturers, Dosing Pumps Suppliers; Submersible pumps for wells: types, characteristics, installation). These pumps are widely used for lifting and pumping working fluid into the reservoir, as well as to maintain reservoir pressure (Belen, 1996).

In recent years, the operation of body parts and components of oil and gas production equipment, including submersible centrifugal pumps, has been constantly exposed to an aggressive environment of mechanical impurities, the destructive activity of formation fluids, and scale deposition

(Blochin et al., 2019). All this leads to corrosive electrochemical destruction of materials. Due to the continuing deterioration of oil production conditions at the fields, corrosion problems are constantly aggravated, 
which requires improving methods for increasing the anticorrosion properties and wear resistance of ESP units (Mikhaylova et al., 2017, 2019; Pogrebnaya \& Mustafayev, 2015).

\section{Formulation of the Problem}

Injecting the working fluid into the reservoir, raising it, as well as maintaining the reservoir pressure is a laborious process that is implemented using the ESP (Pogrebnaya et al., 2018; Pogrebnaya \& Mikhailova, 2018). The purpose of this article is to investigate the prospect of improving the quality of work of submersible centrifugal pumps in oil production, drawing on the experience of oil workers, analyzing the above technologies.

\section{RESEARCH METHODS}

The basis for improving the quality of centrifugal pumps in oil production is a study to ensure the reliability of pumping plants (Begelinger, 1981).

Oil producers are forced to use various methods of protection against negative factors to increase the efficiency of pumping equipment (Ostankov et al., 2018). Such factors include: the introduction of inhibitors into the reservoir fluid, the application of protective coatings of metal and tread, the replacement of materials of pump units with new ones made of ni resist - nickel cast iron and stainless steel (Bikbulatov, 2020). The most applicable and effective anticorrosive agents are metal and tread coatings, and the most productive direction is the optimization of composition, structure and application technology (Ivanovsky, 2002).

The problem of corrosion failure of nodes of oil and gas production equipment, (figure 1) namely submersible centrifugal pumps, is solved by five different methods. One of them is the introduction of corrosion inhibitors into the reservoir fluid, which contribute to the formation of a thin film of oxides at the ESP units, which prevents the destruction of the base material (Brikov \& Markin, 2020). The use of corrosion inhibitors is not an innovation of oil industry workers; the technology of delivering the inhibitor into the formation, into the annulus, using hanging containers, through capillary tubes is important here (Brikov \& Markin, 2018).

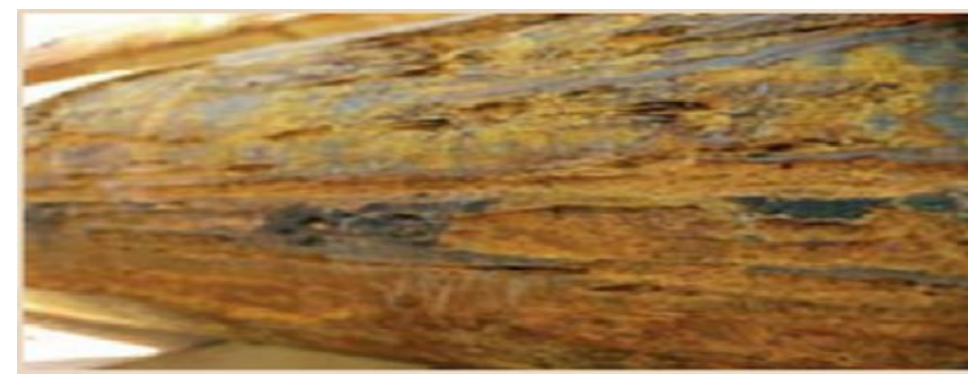

Figure 1: Parts Affected by Corrosion (Ivanovsky, 2011).

Another method involves the replacement of materials of assemblies and body parts of the ESP with new materials with higher corrosion resistance.

The next method consists in applying corrosion-resistant metal protective coatings by high-speed gas-flame spraying based on iron. The use of alloying elements in sprayed materials increases wear and corrosion resistance, makes it possible to reduce porosity, which increases the strength properties of materials and minimizes subfilm corrosion.

Another effective method is the deposition of metal anti-corrosion coatings by the method of electric arc metallization. In this case, significant porosity arises, which requires additional protection with a thick layer of viscous 
impregnation (Practice and prospects of application of protective coatings on housing parts and assemblies of submersible centrifugal pumps, 2015).

Finally, the fifth method is aimed at providing additional corrosion protection using impregnations, including fluorine-containing surfactants (Degtsov et al., 2016).

\section{DISCUSSIONS AND RESULTS}

In our work, we do not try to give a detailed analysis of the operation of submersible centrifugal pumps when applying various types of measures to ensure the reliability of pumping units, but conduct a study based on the available material published by leading oil scientists.

The problem of improving the quality of work of submersible centrifugal pumps using all types of protective coatings on body parts and assemblies is dealt with by the Technological Systems of Protective Coating Limited Liability Company. LLC TSZP is the leader in the domestic coating market. At present, it is a research, engineering center for the development and implementation of gas thermal spraying, plasma and gas-powder surfacing technologies for multifunctional, including nanostructured protective coatings. Significant contribution to the field of improving the quality of work of submersible centrifugal pumps was made by such Russian scientists as Lurie Alexander Zyamovich, Commercial Director of LLC TSZP, Ivanovsky Vladimir Nikolaevich, Head of the Department of Russian State University of Oil and Gas named after I.M Gubkin, Doctor of Technical Sciences, Professor, Yakimov Sergey Borisovich, Manager of the Department of Downhole Operations of TNK-BP OJSC, Zavyalov Viktor Vasilyevich, Head of the Laboratory of OJSC Nizhnevartovsk NIP Ineft, Ph.D. and other.

\section{Protective Metal and Tread Coatings}

Iron-based metal coatings applied to the outer surfaces of hull parts and ESP units with the addition of alloying elements (chromium, nickel, silicon, molybdenum, boron and carbon, which have a more positive electrode potential than the potential of the main metal of the ESP body) are good corrosion protection, but only as long as there are no mechanical damage in the coating. If damage occurs during the installation of the ESP, a galvanic pair is formed: the metal coating becomes the cathode in relation to the housing, and the ESP housing becomes the anode. The process of electrochemical corrosion begins between the coating and the body material, which leads to corrosion of the protected casing of the ESP and to corrosion of the casing(Blochin at al., 2019).

In the process of electrochemical corrosion, the main body material is oxidized, decaying into positively charged ions, into the electrolyte - formation fluid and electrons (figure 2), the anode - body dissolves(Practice and prospects of application of protective coatings on housing parts and assemblies of submersible centrifugal pumps, 2015). 


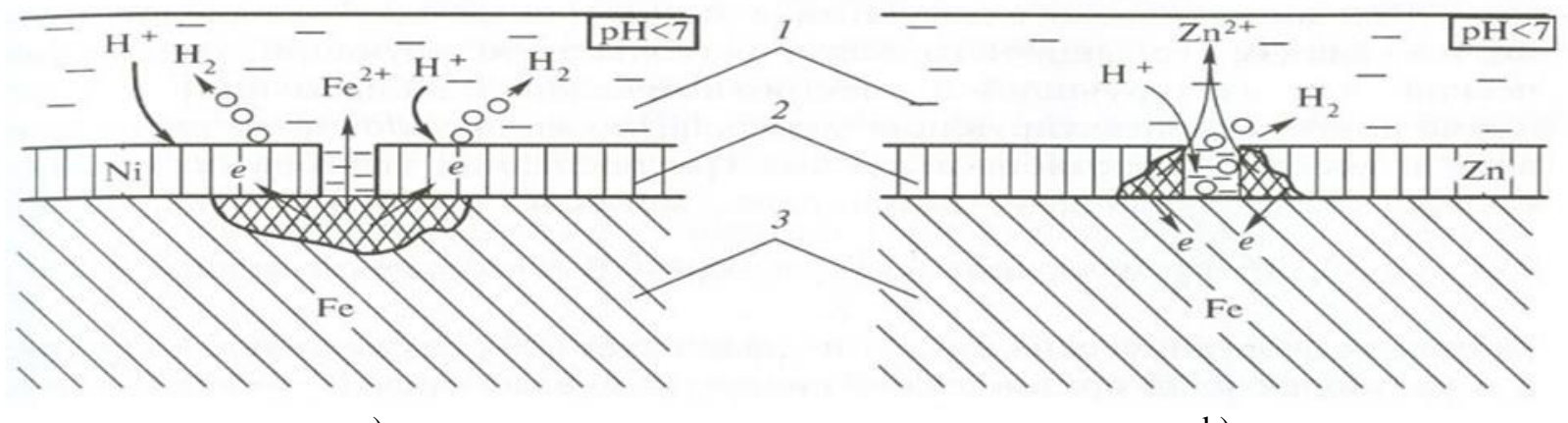

a)

b)

Figure 2: Scheme of the Process of Electrochemical Corrosion(Yasinetsky, 2010)

a) Cathode Coating; b) Anode Coating

1- Electrochemical Corrosion in Violation of the Integrity of the Coating;

2- Acid Solution 3 - ESP Body

Thus, the result is the destruction of the ESP body.

The authors of this study recommend the selection of galvanic pairs of the anode and cathode with the greatest difference in electrochemical potentials between the body part and the coating. A pair of "monel metal" is proposed (an alloy containing up to $67 \%$ nickel and up to $38 \%$ copper) (Ivanovsky et al., 2002).

To solve the problem of subfilm corrosion of body parts and ESP units, electrochemical protection is usually applied. The tread (anode) coating (Al, $\mathrm{Zn}, \mathrm{Mg}$ or their alloys) is applied to a metal one, which has an electrode potential more negative than the potential of a metal coating, the main material of the ESP body and casing. However, in the case of mechanical damage during the installation of the ESP buildings, electrochemical corrosion begins between the tread and the metal coating (see "Scheme of the electrochemical corrosion process on the ESP casing during mechanical damage to the metal and tread coatings") (Degtsov et al., 2016).

If the coating is broken, a galvanic pair is formed between the aluminum or zinc coating, which becomes the anode, and the metal coating or the base metal of the ESP unit, which becomes the cathode with respect to the tread coating. The tread coating is destroyed in this process, preserving the main material of the hull parts and ESP units, on which restoration processes take place (Practice and prospects of application of protective coatings on housing parts and assemblies of submersible centrifugal pumps, 2015).

Tread coatings based on zinc and aluminum alloys remain resistant to sea water for 10-60 years and have the effect of increasing cracks and scratches. For comparison, paint coatings provide stability in sea water for no more than three years, moreover, when they are used in the marine environment, bacteria develop in micropores, which leads to the formation of ulcerative corrosion of the steel casing (Ivanovsky et al., 2002).

Today, metal and tread coatings remain effective methods in the fight against corrosion, and one of the urgent areas for their improvement is the optimization of the composition, structure and application technology. Work in this direction is being carried out by several organizations, in particular "TSZP" together with VNIIGAZ and the Department of Electrochemistry of Lomonosov Moscow State University. These works will allow to choose the most suitable coating option for each specific field, considering the features of its operation. 


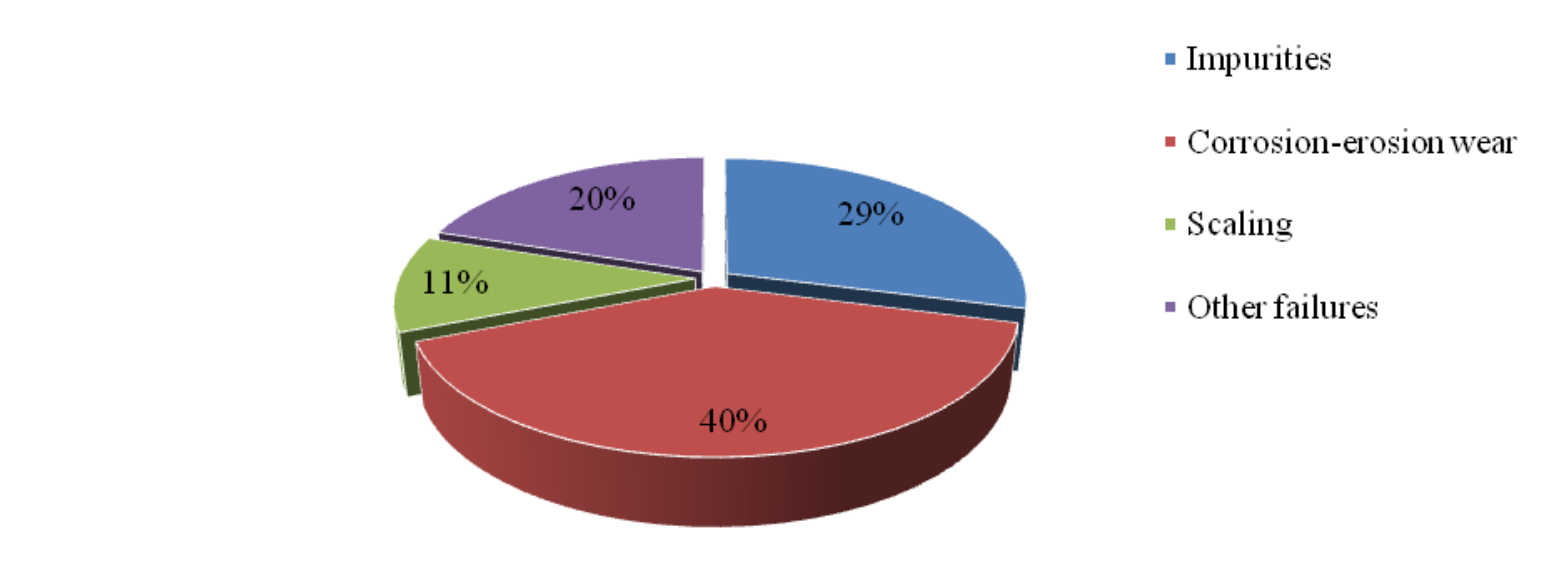

\section{Figure 3: Distribution of ESP Failures for Reasons Related to Complicating Factors. \\ Source: Authors of article}

The methods used to protect the ESP units from corrosion have their drawbacks.

Corrosion inhibitors act for a limited time.

The impregnating materials that are used to protect the coating applied by electric arc metallization act as thermal protection of the ESP units, causing overheating of the parts, which adversely affects the operation of the entire installation.

Replacing the material of the assemblies and body parts of the ESP with stainless steel increases their cost several times, which also leaves the problem of corrosion of the casing string and tubing string unresolved.

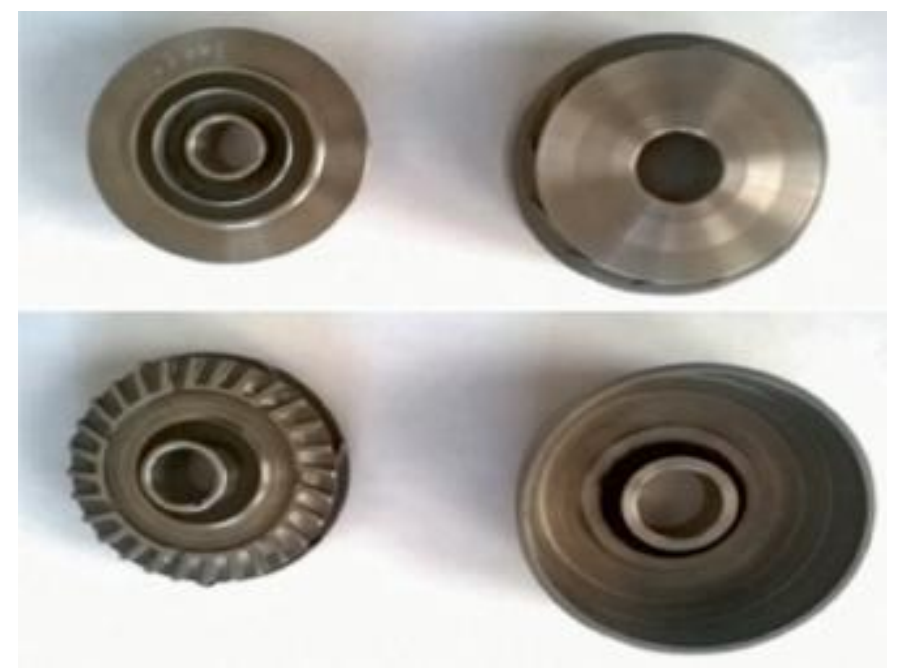

Figure 4: Guide Vanes and Impellers of Steps Made of ni-Resist (Degtsov et al., 2016).

Replacing the materials of the parts of the ESP units, namely, the impellers of the stages of submersible pumps, with a new material - ni - resist - nickel cast iron and stainless steel, which have higher corrosion resistance. Such a material is an alloy of nickel and cast iron (Degtsov et al., 2016). 


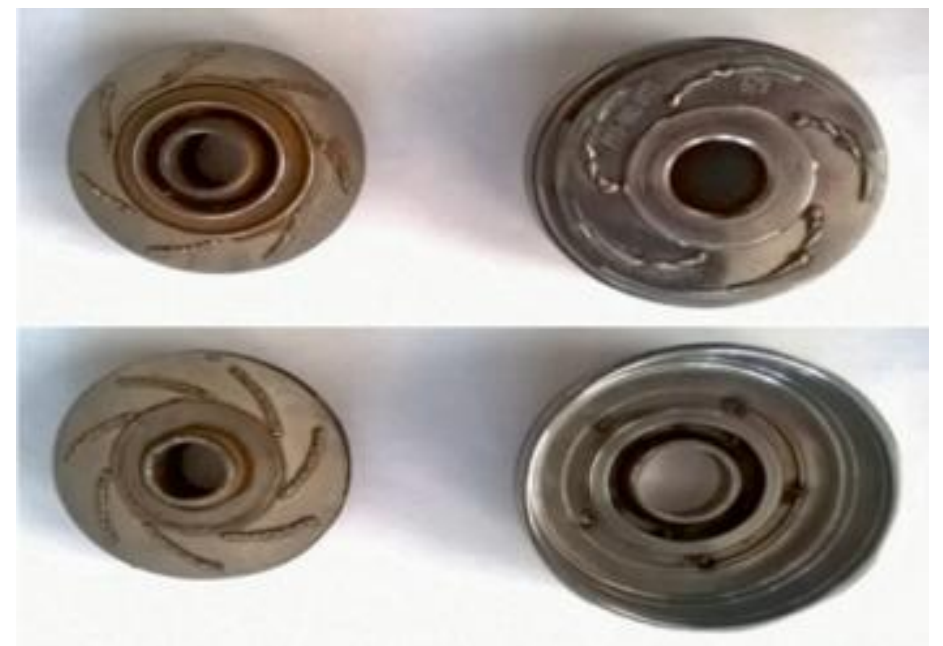

Figure 5: Guide Rails and Impellers of Stainless Steel Steps(Degtsov et al., 2016).

Corresponding studies were conducted on the basis of the laboratory of downhole pumping units of the Department of Machines and Equipment of the Oil and Gas Industry of Gubkin Russian State University of Oil and Gas

(National Research University). The tests were conducted on nickel cast iron impellers and stainless alloy impellers in order to compare and determine the degree of wear under equal conditions (Figure 4 and5). Complex characteristics were measured at the laboratory bench; a fluid with mechanical impurities was used as a model fluid (Hisham A. Mubarak et al., 2003).

The analysis of studies revealed:

- The hydrodynamic characteristics of the impellers change slightly after hydroabrasive wear, sometimes even improve, that is, the pressure and efficiency increase by an average of $5 \%$.

- Small transformations occurred during the study of the characteristics of impellers with wear of the steps. In the operation of these wheels, vibration occurs due to an increase in the gap in the pair "impeller sleeve - bore of the guiding apparatus" of $0.5 \mathrm{~mm}, 4.5 \mathrm{~N}$ for a stainless steel step and $7.7 \mathrm{~N}$ for a ni - resist step. Additional radial load will be $0.9-1.53 \mathrm{kN}$ for a section of 200 steps, which can lead to an emergency.

\section{CONCLUSIONS}

Thus, according to the results of the study, an increase in the operating efficiency of submersible electric centrifugal pump installations was reflected in our analysis of the work of famous scientists of oil industry workers. In oil production, the corrosive destruction of ESP units by $40 \%$ reduces the wear resistance of the existing fund of downhole pumping equipment (Gabor Takacs, 2009). A method for preventing corrosion destruction of oil and gas equipment nodes by introducing inhibitors into the formation fluid (Pogrebnaya \& Mustafayev, 2015). When using corrosion inhibitors, the technology of delivering the inhibitor into the formation, into the annulus, using hanging containers, through capillary tubes is important (Podvintsev, 2011).

The use of metal and tread coatings is considered an effective method in the fight against corrosion, although it has the above-mentioned disadvantages. An important component is the optimization of the composition, structure, and coating technology (Roller Burnishing). This approach makes it possible to choose the most suitable coating option for each specific field, taking into account the peculiarities of its operation and geographic location. Research in this direction is ongoing.

The use of impregnating materials as a protection for the coating deposited by electric arc metallization did not find 
worthy application, since thermal protection causes overheating of parts of the ESP unit, which adversely affects the operation of the entire installation (Molchanov, 2013).

Replacing the material of the parts of the ESP units with ni - resist and stainless steel allows us to draw the following conclusions:

- $\quad$ ESP impellers made of stainless steel have higher wear resistance compared to casting impellers from ni - resist;

- The wear of the parts of the impellers of stainless steels is $0.091 \mathrm{~g} / \mathrm{h}$, and the wear of the parts of the impellers of $\mathrm{ni}$ - resist is $0.108 \mathrm{~g} / \mathrm{h}$;

- Two support steps of the ESP impellers made of stainless steel are more wear-resistant, in comparison with impellers from ni - resist. Stainless steel ESPs impellers are recommended for use in wells with highly abrasive mechanical impurities with a concentration of up to $1 \mathrm{~g}$ per 1 liter of formation fluid;

- Wear during operation of the impellers from $\mathrm{Ni}$ - resist is much higher than the wear of impellers made of stainless alloy;

- In the extraction of oil with highly abrasive mechanical impurities, the use of steel impellers is necessary to include in the uniform technical requirements additions regarding the use of materials for the manufacture of ESPs.

\section{FUNDING}

The article was completed without financial support.

\section{Conflict of Interest}

There is no conflict of interest.

\section{REFERENCES}

1. Begelinger A. ReibungVerschleip und BetriebsrauhigkeitbeiverschiedenenLagerwerkstoffen. IndAnz, 1981, Vol. 103, No. 24,pp. $64-67$.

2. Belen P., Kumar K.C.H, Wolman's P. Thermodynamic assessment of the Ni - Ti phase diagram. Z. Metallkde,1996, Vol. 87, No.1, pp. 2-13.

3. Bikbulatov O.V. Results of implementation of ASPD-A in TSDNG-4 “T”' TPP “Kogalymneftegas". Engineering practice, 2020, No. 1 .

4. Blochin V.A., DorosinskyA.Yu., Markin A.N. The System of detection of local corrosion processes at early stages. Territory Neftegaz, 2019, No. 4,pp. 44-48.

5. Brikov A.V., Markin A.N. Oil Field Chemistry: Practical Guide to Combating Salt Formation, 2018, pp. 335.

6. Brikov A.V., Markin A.N.Organization of the system of application of oil field chemistry reagents in oil and gas production enterprises. Oil-field business, 2020, Vol. 3, No. 615,pp. 59-65. doi: 10.30713/0207-2351-2020-3(615)-59-65.

7. Degtsov A.V., Sokolov N.N., Ivanovsky A.V. To the question of selection of material of stages of electric centrifugal pump for complicated operating conditions. Territory of NEFTVAZ, 2016, No. 11, pp. 88-91.

8. FariborzKavoussi. ESP life cycle. OMV Exploration and Production. 16.9.2013. 
9. Gabor Takacs. Design and analysis of ESP installations. Electrical Submersible Pumps Manual,2009, pp. 187-247. doi: 10.1016/B978-1-85617-557-9.00005-1.

10. Hisham A. Mubarak, Farooq A. Khan, Dr Mehmet M. Oskay.ESP failures, analysis, solutions in divided zone - case study. Society of Petroleum Engineers, 2003, pp. 81488.

11. Industrial Pumps, Screw Pump Manufacturers, Dosing Pumps Suppliers. Available at: padmavatisalesandservices.com.

12. Ivanovsky V.N. Corrosion of borehole equipment and methods of protection from it. Territory of NEFTVAZ, 2011, Vol. 1, No. 18.

13. Ivanovsky V.N., Darishchev V.I., Sabirov A.A., Kashtanov V.S., Pekin S.S. Borehole pump installations for oil production,2002, pp. 824.

14. Mikhaylova S.V., Pogrebnaya I.A. Increasing the efficiency of centrifugal pumps. Journal of Dagestan State Technical University, 2019, Vol. 46, No. 2, pp. 20-27. doi: 10.21822/2073-6185-2019-46-2-20-27.

15. Mikhaylova S.V., Zakirov E.A, Pogrebnaya I.A. Operation of the associated petroleum gas drying unit on the example of unit No. 4 of the Nizhnevartovsk gas processing complex limited liability company. Materials of the International scientific and practical conference of students, postgraduates and young scientists "New technologies for the oil and gas region". Tyumen: TIU, 2017. pp. 87-90.

16. Molchanov A.G. Machines and equipment for oil and gas production. Moscow,2013. pp. 588.

17. Ostankov N.A., Nizamov R.N., Korolev D.V. Use of ASPO inhibitors in well equipment and pipeline transport facilities. Engineering practice, 2018, No. 5.

18. Podvintsev I.B. Oil refining. Practical introduction course, 2011, pp. 120.

19. Pogrebnaya I.A, Mikhailova S.V. Centrifugal Pumps. Questions of modern science: a collective scientific monography,2018. pp. $59-75$.

20. Pogrebnaya I.A, Mikhailova S.V., KazarinovYu.I. Basics of hydraulics and hydropermotor. Moscow,2018. pp. 90.

21. Pogrebnaya I.A, Mustafayev A.K. The problem of cavitation in oil and gas equipment. Article Experience, current problems and prospects of oil and gas complex development. Materials of the 5 Regional Scientific and Practical Conference of Students, Postgraduate Students and Scientists. Tyumen: TumGNSU, 2015. pp. 368-372.

22. Practice and prospects of application of protective coatings on housing parts and assemblies of submersible centrifugal pumps. Website of the research organization "Technological systems of protective coatings", 2015. Available at: https://www.tspc.ru/press-center/articles/practice-and-prospects-of-application-of-protective-coatings-on-casing-details-andnodes-of-submersial-centrifugal-pumps/.

23. Pittala, Suresh, and T. Diriba. "Computational Fluid Dynamics Analysis of Impeller Design For A Pump." International Journal of Mechanical Engineering (IJME) 5.4.

24. Roller Burnishing. Available at: mollart.com/tooling/roller.

25. Sachin, Chaudhari, and Kaumil B. Shah. "Solar Photovoltaic Fed Induction Motor for Water Pumping System Using Mppt Algorithm."International Journal of Electrical and Electronics Engineering (IJEEE) 7. 3, Apr - May 2018, 31-42

26. Shukla, Shyam Narayan, Ruchi Khare, and Vishnu Prasad. "Cfd Approach for off-Design Efficiency Improvement of Double Suction Centrifugal Pump."International Journal of Mechanical and Production Engineering Research and Development (IJMPERD) 7. 5, Oct 2017, 289-300 
27. Submersible pumps for wells: types, characteristics, installation. Available at: energomir.net/vodoprovod.

28. Teja, Chsai, and M. Murali Krishna. "Design of Centrifugal Pump Impeller and Its Effects on Cavitation. "International Journal of Mechanical and Production Engineering Research and Development IJMPERD)9. 4, Aug 2019, 753-760

29. Yasinetsky V.V. Theoretical foundations of chemistry: lecture notes for students of chemical and technological specialties,2010. pp. 176. 
